\title{
ANCANGAN ANALISIS BAHASA DI RUANG PUBLIK: STUDI LANSKAP LINGUISTIK KOTA SURAKARTA DALAM MEMPERTAHANKAN TIGA IDENTITAS ${ }^{1}$
}

\author{
Eric Kunto Aribowo \\ Pendidikan Bahasa dan Sastra Daerah \\ Universitas Widya Dharma \\ erickunto@unwidha.ac.id \\ Rahmat \\ Pendidikan Bahasa Jawa \\ Universitas Sebelas Maret \\ rahmat_pbj@staff.uns.ac.id \\ Arif Julianto Sri Nugroho \\ Manajemen \\ Universitas Widya Dharma \\ arifjulianto72@yahoo.com
}

\section{Pendahuluan}

Kota Surakarta merupakan salah satu kota yang dapat mewakili kondisi keberagaman bahasa dan budaya di Indonesia. Selain dikenal sebagai kota budaya dan pusat ekonomi (Badan Pusat Statistik Kota Surakarta, 2017, 2018), Surakarta dihuni oleh dua keturunan asing terbesar di Indonesia, keturunan Arab dan keturunan Tionghoa (Aribowo, 2017). Dua komunitas ini senantiasa mempertahankan bahasa nenek-moyangnya hingga saat ini, meskipun muncul beberapa fenomena menampakkan perpaduan antara budaya asli mereka dengan budaya Indonesia akibat kontak bahasa yang terjadi sejak puluhan, bahkan ratusan tahun yang lalu (Aribowo, 2014a, 2014b, 2015).

Keberagaman bahasa Indonesia, Arab, dan Tionghoa yang ada di kota Surakarta tidak hanya dapat dilihat dari bahasa pertuturan, namun pada bahasa tulis yang pada beberapa tahun terakhir ini mewarnai ruang-ruang publik. Meskipun penggunaan bahasa Indonesia di ruang publik secara jelas diatur dalam UU RI No 24 Tahun 2009 tentang Bendera, Bahasa, dan Lambang Negara, serta Lagu Kebangsaan, faktanya dalam praktik dan implementasi merupakan hal yang berbeda (lihat Gambar 1). Beberapa studi yang telah dilakukan mengarahkan bahwa alasan ekonomi menjadi faktor kuat penggunaan bahasa asing (terutama bahasa Inggris) daripada bahasa Indonesia atau bahasa daerah (Kusumaningsih, Sudiatmi, \& Muryati, 2013; Riani, 2014; Wijana, 2014).

\footnotetext{
${ }^{1}$ Aribowo, E. K., Rahmat, Arif Julianto Sri Nugroho. (2018). “Ancangan Analisis Bahasa di Ruang Publik: Studi Lanskap Linguistik Kota Surakarta dalam Mempertahankan Tiga Identitas”. Semiloka dan Deklarasi Pengutamaan Bahasa Negara. Surakarta: Universitas Sebelas Maret.
} 


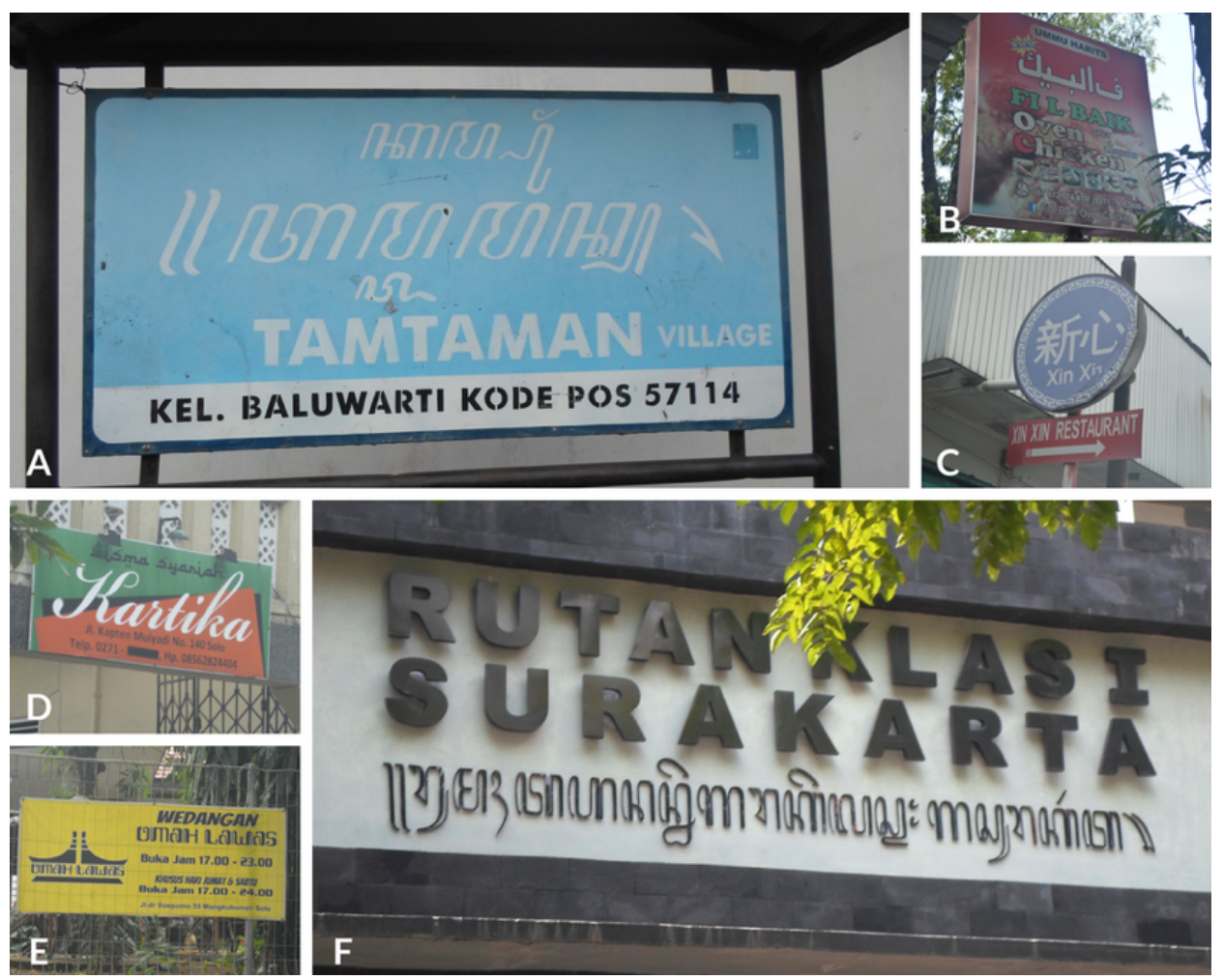

Gambar 1 Beberapa contoh fenomena lanskap linguistik kota Surakarta.

Foto (Eric Kunto Aribowo, 2018)

Studi bahasa pada ranah publik, atau yang dikenal dengan Lanskap Linguistik (selanjutnya disebut LL) merupakan kajian (sosio)linguistik modern yang melibatkan studi onomastik, semiotik, dan spasial (Akindele, 2011; Aribowo, 2017; Nash, 2016; Wolf, Hans-Georg Wolf Zweitgutachter, Bernhard Bielick, \& Magdalena, 2012). Studi ini melibatkan bahasa yang tertuang dalam petunjuk jalan, papan iklan, nama jalan, nama daerah, nama toko, dan petunjuk-petunjuk umum pada bangunan pemerintah (Landry \& Bourhis, 1997:25). Meskipun dapat dikatakan sebagai cabang ilmu baru, pengkajian LL secara serempak telah dilakukan di beberapa negara seperti: Malaysia (Manan, David, Dumanig, \& Naqeebullah, 2015), Singapura (Tang, 2016), Brunei Darussalam (Coluzzi, 2012), Timor-Leste (Taylor-Leech, 2012), Kamboja (Kasanga, 2012), Hongkong (Wolf et al., 2012), Jepang (Backhaus, 2006, 2007), Bostwana (Akindele, 2011), negara-negara Baltik (Kreslins, 2003), Australia Selatan (Koschade, 2016), Taipei (Curtin, 2015), dan Bosnia (Lay, 2015).

\section{Urgensi Kajian Lanskap linguistik}

Meningkatnya penggunaan bahasa pada nama jalan, poster, iklan, papan informasi dan himbauan resmi pemerintah telah menjadi topik hangat para akademisi belakangan ini (Koschade, 2016; Rubdy \& Said, 2015; Tang, 2016). Beberapa negara atau kota juga telah menerbitkan peraturanperaturan terkait kebijakan bahasa yang digunakan dalam ranah publik. Regulasi terkait LL secara simultan juga mengatur kebijakan bahasa pada ranah pendidikan, media, kehidupan sosialekonomi, dan sebagainya. Beberapa studi menunjukkan adanya pengaruh yang kuat antara 
kebijakan bahasa dan penggunaan bahasa di ranah publik (Cenoz \& Gorter, 20o6; Manan et al., 2015; Spolsky, 2004; Taylor-Leech, 2012).

Spolsky (2004) memilah antara kebijakan dan praktik yang disebutnya sebagai ideologi, praktik dan manajemen. Menurut pengamatannya "...the real language policy of a community is more likely to be found in its practices than in management” (Spolsky, 2004). Secara aktual, praktikpraktik penggunaan bahasa dapat mengungkap ideologi bahasa masyarakat lokal dalam kaitannya dengan kebijakan bahasa nasional.

\section{Beberapa Fenomena Lanskap Linguistik Belakangan Ini}

LL mengklaim bahwa tanda yang ada pada lanskap berupa teks ilustratif yang dapat dibaca dan difoto yang dapat dibedah secara linguistis dan kultural (Gorter, 2006; Shohamy, Ben-Rafael, \& Barni, 2010; Shohamy \& Gorter, 2009). Tanda yang dimaksud merupakan tanda yang digunakan dalam rangka diseminasi pesan umum kepada publik dalam bentuk informasi, petunjuk, peringatan, dan semacamnya. Tanda ini juga sering kali muncul pada konteks komersial seperti pemasaran dan iklan yang fungsi utamanya untuk menarik perhatian terhadap sebuah produk atau bisnis (Backhaus, 2007; Kasanga, 2012; Manan et al., 2015; Wolf et al., 2012). Fokus utama LL mengungkap visibility dan arti penting bahasa-bahasa tulis yang digunakan pada ranah publik. Secara singkat dikatakan bahwa LL merupakan potret situasi kebahasaan di ranah publik (biasanya melibatkan negara atau kota) tentang pola-pola umum penggunaan bahasa, kebijakan bahasa, sikap bahasa, dan konsekuensi kontak bahasa yang terjalin dalam waktu jangka panjang.

Penggunaan bahasa yang berbeda untuk sebuah tanda juga merefleksikan kekuasaan, status, dan kepentingan ekonomi dari bahasa yang ada di kota Surakarta. Dari beberapa studi ditemukan bahwa tanda yang berbasis multibahasa cenderung menyematkan bahasa Inggris sebagai salah satu bahasa yang digunakan, tidak hanya terjadi di kota-kota besar dan ibukota provinsi bahkan hingga ke desa-desa (Kusumaningsih et al., 2013; Riani, 2014; Wijana, 2014). Penggunaan bahasa Inggris pada ranah bisnis bertujuan untuk meningkatkan penjualan dan memunculkan motivasi ekonomi di kalangan konsumen. Beberapa penyebab menyebarnya bahasa Inggris ialah faktor globalisasi.

\section{Ancangan Kajian Lanskap Linguistik}

\subsection{Bahasa apa saja yang mendominasi LL di Surakarta}

Keberagaman bahasa pada ruang publik di Surakarta setidaknya menghadirkan lima bahasa: Indonesia, Jawa, Inggris, Arab, Tionghoa; dan kombinasi di antara bahasa tersebut (lihat Gambar 1). Penggunaan bahasa Indonesia dan bahasa Jawa (Gambar 1E dan 1F) menjadi hal yang lazim mengingat Surakarta merupakan pusat budaya dengan Keraton Surakarta Hadiningrat yang menjadi simbolnya (Damayanti \& Handinoto, 2005; Hardiyanti, Antariksa, \& Hariyani, 2005).

Penggunaan bahasa Inggris di seluruh dunia menandakan pengaruh globalisasi yang mengarah pada prinsip-prinsip ekonomi seperti pemasaran, produksi, dan konsumsi. Penggunaan bahasa Inggris dalam dunia ekonomi tampaknya memiliki tendensi untuk meningkatkan penjualan 
dan menghadirkan motivasi ekonomi. Penggunaan bahasa Inggris juga memicu isu identitas dan kekuasaan serta memiliki konsekuensi terhadap keseimbangan bahasa-bahasa berbeda yang hidup pada situasi di wilayah multibahasa, termasuk Surakarta.

Maraknya penggunaan bahasa Arab banya didominasi di daerah Kampung Arab Pasar Kliwon sebagai wilayah konsentrasi pemukiman keturunan Arab (Aribowo, 2015, 2017). Meningkatnya tren bisnis halal maupun syariah (Rahmadhani, 2015; Sari \& Sudradjat, 2013) juga turut mendukung hadirnya bahasa Arab di ruang publik. (Gambar 1B dan 1D).

\subsection{Identitas yang mewujud dalam LL}

Salah satu cara untuk mengidentifikasi identitas yang termuat pada teks di LL adalah dengan menganalisis tipografi penulisannya (Curtin, 2015; Manan et al., 2015; Taylor-Leech, 2012). Setidaknya ditemukan empat variasi sistem penulisan di ruang publik kota Surakarta, sitem penulisan yang ditulis dengan memanfaatkan aksara atau huruf Latin (Gambar 1), Jawa (Gambar 1A dan 1F), Arab (Gambar 1B), dan Pinyin Tionghoa (Gambar 1C). Kondisi ini mengukuhkan masih kuatnya identitas keindonesiaan, kejawaan, kearaban, dan ketionghoaan yang dimiliki oleh masyarakat Surakarta.

Beberapa fenomena lain yang terjadi adalah hadir sebuah tulisan yang ditulis dengan huruf Latin, tetapi jenis hurufnya menyerupai huruf lain, misalnya frasa "wisma syariah" yang jenis hurufnya menyerupai huruf Arab (Gambar 1D) dan frasa "omah lawas" yang mereplika huruf Jawa (Gambar 1E). Sistem penulisan yang menyerupai aksara lain ini merupakan simbol sebuah identitas grup, baik etnisitas maupun sosial (Sutherland, 2015; Taylor-Leech, 2012). Sistem penulisan ini disebut Sutherland (2015) dengan istilah mimikri (mimicry) yang didefinisikan sebagai sebuah keputusan untuk membuat teks pada sebuah sistem penulisan yang secara visual menyerupai bentuk sistem penulisan lainnya.

\subsection{Komposisi penggunaan bahasa oleh pemerintah dan non-pemerintah}

Selain dalam hal distribusi bahasa, analisis juga dapat dilakukan dengan jalan memerikan komposisi bahasa yang digunakan pada bangunan atau gedung yang dikelola oleh pemerintah dan non-pemerintah. Pada bangunan yang dikelola oleh pemerintah memiliki kecenderungan menggunakan bahasa Indonesia, meskipun pada beberapa kondisi dikombinasikan dengan aksara Jawa (Gambar 1F). Kebalikannya, bangunan yang dikelola oleh non-pemerintah bertendensi menggunakan bahasa non-Indonesia (Gambar $\mathbf{1 A}, \mathbf{1 B}$, dan $\mathbf{1 C}$ ). Kasus yang sama pada penggunaan bahasa Inggris, Portugis, dan Indonesia yang terjadi di Timor-Leste (Taylor-Leech, 2012). Bahkan, sebuah universitas di Jepang mulai memunculkan bahasa Inggris di lingkungan kampus dalam rangka stimulasi internasionalisasi kampus (Wang, 2015). 


\subsection{Respons masyarakat terhadap penggunaan bahasa di ranah publik}

Respons masyarakat menjadi salah satu topik yang wajib digali untuk mengetahui bahasa yagn dibutuhkan secara riil oleh masyarakat yang berperan sebagai konsumen/pembaca. Beberapa contoh informasi yang perlu dikuak dengan mengadaptasi kuesioner dari (Akindele, 2011; Moriarty, 2014; Wang, 2015).

1. Seberapa penting penggunaan bahasa-bahasa Indonesia, Jawa, Inggris, Arab, Tionghoa pada ranah publik?

2. Apakah menurut Anda bahasa-bahasa tersebut dapat memudahkan pengguna/pembaca masyarakat umum dalam mendapatkan informasi?

3. Apakah menurut Anda bahasa-bahasa tersebut dapat memudahkan para wisatawan asing untuk lebih memahami bahasa dan budaya kota Surakarta?

4. Bahasa apa yang menurut Anda paling utama digunakan? Apa alasannya?

5. Apakah Anda dapat memberikan contoh penggunaan bahasa yang baik pada ranah publik?

6. Apa pendapat Anda mengenai penggunaan aksara Latin, Jawa, Arab, dan Pinyin Tionghoa yang terdapat pada ruang publik?

7. Apa pendapat Anda tentang penggunaan karakter/huruf Latin yang menyerupai hurufhuruf Jawa, Arab, dan Pinyin Tionghoa?

\section{Metode Penelitian Lanskap Linguistik}

Pada umumnya, kajian LL melibatkan metode penelitian kualitatif yang ditempuh dengan jalan melakukan dokumentasi objek LL menggunakan kamera digital. Secara metodologis, analisis LL mengandalkan fotografi dan analisis visual. Pengumpulan data berfokus pada keterlibatan fotografi yang tervisualisasi dari teks yang berada pada tanda-tanda di ruang publik. Ruang lingkupnya termasuk tempat-tempat yang secara geografis merupakan lokasi strategis seperti stasiun, bandara, terminal, supermarket, perkantoran, pusat bisnis, destinasi wisata, rumah sakit, dan lain sebagainya.

\section{Penutup}

Studi LL mengindikasikan bagaimana sikap bahasa masyarakat terhadap bahasa-bahasa yang dikuasainya. Meskipun pada faktanya bahasa-bahasa asing banyak digunakan di ranah publik, tetapi bahasa tersebut bukan/tidak menjadi bahasa yang dikuasai -dituturkan pada percakapan setiap hari. Bahasa-bahasa asing yang mendominasi lanskap di Indonesia, khususnya kota Surakarta merupakan bahasa-bahasa yang dipandang memiliki nilai dan kekuatan ekonomi yang lebih apabila dibandingkan dengan bahasa-bahasa daerah yang lebih dikuasai masyarakat setempat. Absennya bahasa-bahasa daerah -yang menurut jumlah penuturnya merupakan bahasa mayoritas- tentu harus dipandang secra optimistis agar dapat dihadirkan kembali dengan menyusun kebijakan Bahasa yang melibatkan berbagai pihak, tidak hanya Badan Bahasa namun 
juga melibatkan Kemenkeu, Kemenkominfo, Kemenhub, Kemendagri, Kemenperin, Kemendag, Kemenpar, Badan Ekonomi Kreatif, dan kementerian/badan terkait lainnya.

\section{Daftar Pustaka}

Akindele, D. O. (2011). Linguistic Landscapes as Public Communication: A Study of Public Signage in Gaborone Botswana. International Journal of Linguistics, 3(1), 1-11. http://doi.org/10.5296/ijl.v3i1.1157

Aribowo, E. K. (2014a). Bahasa Hibrida: Bukti Harmoni Akulturasi Budaya Arab-Nusantara. In M. Fasya \& M. Zifana (Ed.), Keberagaman Budaya dalam Bingkai Keberagaman Bahasa (hal. 188194). Bandung: UPI Press. http://doi.org/10.17605/OSF.IO/XUNGP

Aribowo, E. K. (2014b). Pemertahanan Bahasa Arab-Nusantara: Bagaimana Ekologi Memainkan Perannya. In M. Masruhi \& Habib (Ed.), The Arabic Culture Identity: Facts and Challenges (hal. 131-147). Yogyakarta: IDEA Press. http://doi.org/10.176o5/OSF.IO/XDQYT

Aribowo, E. K. (2015). Selamatkan Perkawinanmu, Selamatkan Bahasamu: Catatan mengenai Dampak Positif Perkawinan Endogami terhadap Bahasa Masyarakat Keturunan Arab di Pasarkliwon Surakarta. In H. Purwoko, A. Subiyanto, W. Sayekti, T. M. D. Pasaribu, Y. Thianto, P. Sarmah, \& Z. Goebel (Ed.), Language Maintenance and Shift V (hal. 271-275). Semarang: Master Program in Linguistics, Diponegoro University. Diambil dari http://eprints.undip.ac.id/55372/

Aribowo, E. K. (2017). Linking Arabic, Islam, and Economy: Onomastics on Bussiness Name of People of Arab Descent in Indonesia. KARSA:Journal of Social and Islamic Culture, 25(2), 284306. http://doi.org/10.19105/karsa.v25i2.139o

Aribowo, E. K. (2018). Beberapa Contoh Fenomena Lanskap Linguistik Kota Surakarta. figshare. https://doi.org/10.6o84/mg.figshare.6728462

Backhaus, P. (2006). Multilingualism in Tokyo: A Look into the Linguistic Landscape. International Journal of Multilingualism, 3(1), 52-66. http://doi.org/10.1080/147907106o8668385

Backhaus, P. (2007). Linguistic Landscapes: A Comparative Study of Urban Multilingualism in Tokyo. Clevedon: Multilingual Matters. http://doi.org/10.1093/wsr/wspoo6

Badan Pusat Statistik Kota Surakarta. (2017). Kota Surakarta dalam Angka 2017. Surakarta: Badan Pusat Statistik.

Badan Pusat Statistik Kota Surakarta. (2018). Sensus Ekonomi 2016 Analisis Hasil Listing Potensi Ekonomi Surakarta. Surakarta: Badan Pusat Statistik.

Cenoz, J., \& Gorter, D. (2006). Linguistic Landscape and Minority Languages. International Journal of Multilingualism, 3(1), 67-8o. http://doi.org/10.108o/1479o7106o8668386

Coluzzi, P. (2012). The Linguistic Landscape of Brunei Darussalam: Minority Languages and the Threshold of Literacy. Southeast Asia: A Multidisciplinary Journal, 12(1), 1-12. Diambil dari https://umexpert.um.edu.my/file/publication/ooo11613_86551.pdf

Curtin, M. L. (2015). Creativity in polyscriptal typographies in the linguistic landscape of Taipei. Social Semiotics, 25(2), 236-243. http://doi.org/10.108o/10350330.2015.1010315

Damayanti, R., \& Handinoto. (2005). Kawasan "Pusat Kota" dalam Perkembangan Sejarah Perkotaan di Jawa. Dimensi: Journal of Architecture and Built Environment, 33(1), 34-42. http://doi.org/https://doi.org/10.9744/dimensi.33.1

Gorter, D. (2006). Linguistic Landscape: A New Approach to Multilingualism. Clevedon: Multilingual Matters.

Hardiyanti, N. S., Antariksa, \& Hariyani, S. (2005). Studi Perkembangan dan Pelestarian Kawasan 
Keraton Kasunanan Surakarta. Dimensi: Journal of Architecture and Built Environment, 33(2), 112-124. http://doi.org/https://doi.org/10.9744/dimensi.33.2

Kasanga, L. A. (2012). Mapping the linguistic landscape of a commercial neighbourhood in Central Phnom Penh. Journal of Multilingual and Multicultural Development, 33(6), 553-567. http://doi.org/10.1080/o1434632.2012.683529

Koschade, A. (2016). Willkommen in Hahndorf: A Linguistic Landscape of Hahndorf, South Australia. International Journal of Humanities and Cultural Studies, 3(1), 692-716.

Kreslins, J. (2003). Linguistic Landscape in the Baltic. Scandinavian Journal of History, 28(1), 165-174. http://doi.org/10.1080/03468750310003659

Kusumaningsih, D., Sudiatmi, T., \& Muryati, S. (2013). Pengidonesiaan Kata dan Ungkapan Asing pada Nama Badan Usaha, Kawasan, dan Gedung.Jurnal Pendidikan, 22(3), 267-286.

Lay, R. E. (2015). Linguistic Landscape of Main Streets in Bosnia and Herzegovina. Diambil dari http://dc.etsu.edu/honors

Manan, S. A., David, M. K., Dumanig, F. P., \& Naqeebullah, K. (2015). Politics, economics and identity: mapping the linguistic landscape of Kuala Lumpur, Malaysia. International Journal of Multilingualism, 12(1), 31-5o. http://doi.org/10.108o/14790718.2014.905581

Moriarty, M. (2014). Contesting language ideologies in the linguistic landscape of an Irish tourist town. International Journal of Bilingualism, $18(5), \quad 464-477$. http://doi.org/10.1177/13670o6913484209

Nash, J. (2016). Is linguistic landscape necessary? Landscape Researchch, 41(3), 380-384. http://doi.org/10.108o/o1426397.2016.1152356

Rahmadhani, E. (2015). Pengaruh Atribut Produk Halal terhadap Keputusan Pembelian Kosmetik Wardah pada Mahasiswa-Mahasiswi Departemen Ilmu Administrasi Niaga/Bisnis. Jurnal Niaga \& Bisnis, $2(1) . \quad$ Diambil dari https://jurnal.usu.ac.id/index.php/Jurnal_niaga/article/view/10893

Riani. (2014). Dominasi Bahasa Inggris pada Nama Badan Usaha di Yogyakarta. Widyaparwa, 42(2), 141-152. Diambil dari http://www.widyaparwa.com/index.php/widyaparwa/article/view/84

Rubdy, R., \& Said, S. Ben. (2015). Conflict, Exclusion and Dissent in the Linguistic Landscape. New York: Palgrave Macmillan.

Sari, D. K., \& Sudradjat, I. (2013). Analisis Pengaruh Labelisasi Halal terhadap Keputusan Pembelian Produk Makanan Impor dalam Kemasan pada Mahasiswa Kedokteran Universitas Sumatera Utara. Jurnal Ekonomi dan Keuangan, 1(4), 49-56.

Shohamy, E., Ben-Rafael, L., \& Barni, M. (2010). Linguistic Landscape in the City. Bristol: Multilingual Matters.

Shohamy, E., \& Gorter, D. (2009). Linguistic Landscape: Expanding the Scenery. New York dan Loncon: Routledge. http://doi.org/10.4324/978020393096o

Spolsky, B. (2004). Language Policy. Cambridge: Cambridge University Press.

Sutherland, P. (2015). Writing System Mimicry in the Linguistic Landscape. SOAS Working Papers in Linguistics, $\quad 17(1), \quad 147-167 . \quad$ Diambil dari https://www.soas.ac.uk/linguistics/research/workingpapers/volume-17/file105419.pdf

Tang, H. K. (2016). Linguistic Landscaping in Singapore: The Local Linguistic Ecology and the Roles of English. Lund University.

Taylor-Leech, K. J. (2012). Language choice as an index of identity: Linguistic landscape in Dili, Timor-Leste. International Journal of Multilingualism, 9(1), $15-35$. http://doi.org/10.108o/14790718.2011.583654 
Wang, J.-J. (2015). Linguistic Landscape on Campus in Japan- A Case Study of Signs in Kyushu University. Intercultural Communication Studies XXIV, 24(1), 123-144. Diambil dari https://web.uri.edu/iaics/files/o8.Jing-Jing-Wang-.pdf

Wijana, I. D. P. (2014). Bahasa, Kekuasaan, dan Resistansinya: Studi Tentang Nama-Nama Badan Usaha di Daerah Istimewa Yogyakarta. Humaniora, 26(1), 56-64. Diambil dari https://journal.ugm.ac.id/jurnal-humaniora/article/view/470o

Wolf, H.-G., Hans-Georg Wolf Zweitgutachter, H., Bernhard Bielick, H., \& Magdalena, A. (2012). English in the Linguistic Landscape of Hong Kong: A Case Study of Shop Signs and Linguistic Competence. Universität Potsdam. Diambil dari http://opus.kobv.de/ubp/volltexte/2013/6412/ 